\title{
Memórias, Identidades e Educação Quilombola: Santa Rosa dos Pretos (MA) como contexto e texto
}

Memorias, Identidades y Educación Quilombola: Santa Rosa dos Pretos (MA) como contexto y texto

Memories, Identitiesand Quilombola Education: Santa Rosa dos Pretos (MA) as contextandtext

Gleydson de Castro Oliveira ${ }^{1}$

\begin{abstract}
Resumo
Este artigo tem como objetivo discutir os conceitos de Memórias e Identidades em interface com a Educação Quilombola a partir da experiência no Projeto de Teatro de Bonecos "Histórias e memórias quilombolas em cena", realizado em 2016 no Território Quilombola Santa Rosa dos Pretos, localizado no município de Itapecuru-Mirim (MA). Além de pensar esse território como contexto e texto (CARRIL, 2017) para a sala de aula.
\end{abstract}

Palavras-chave: Memórias; Identidades; Educação Quilombola; Santa Rosa dos Pretos (MA).

\section{Resumen}

Este artículo tiene como objetivo discutir los conceptos de Memorias e Identidades en interface con la Educación Quilombola a partir de la experiencia en el Proyecto de Teatro de Títeres "Historias y memorias quilombolas en la escena", realizado en 2016 en el Territorio Quilombola Santa Rosa dos Pretos, ubicado en el municipio de Itapecuru-Mirim (MA). Además de pensar ese territorio como contexto y texto (CARRIL, 2017) para la aula.

Palabras-clave: Memorias; Identidades; EducaciónQuilombola; Santa Rosa dos Pretos (MA).

\begin{abstract}
This article aims to discuss the concepts of Memories and Identities in interface with Quilombola Education from the experience in the Puppet Theater Project "Quilombola Stories and Memories on the Scene", held in 2016 in the Quilombola Territory Santa Rosa dos Pretos, located in city of Itapecuru-Mirim (MA). Besides thinking this territory as context and text (CARRIL, 2017) for the classroom.
\end{abstract}

Keywords: Memories; Identities; Quilombola Education; Santa Rosa dos Pretos (MA).

\section{Introdução}

Resistindo de uma ponta a outra do Brasil, os territórios quilombolas se organizam e se configuram das mais distintas maneiras. O contexto sócio-histórico em que se constituíram, as terras onde estão situados e as estratégias e relações estabelecidas dentro - sujeito-natureza e sujeito-sujeito - e fora das comunidades são elementos que configuram cada um dos mais de

\footnotetext{
${ }^{1}$ Mestrando em História da África, da Diáspora e dos Povos Indígenas pela Universidade Federal do Recôncavo da Bahia (UFRB); Cachoeira, Bahia, Brasil. Licenciado em Teatro pela Universidade Federal do Maranhão (UFMA); São Luís, Maranhão, Brasil. E-mail: gc.pesquisateatro@gmail.com.
} 
mil territórios ${ }^{2}$ que se auto definem no país como quilombolas. Esses aspectos também acionam e intervêm intrinsecamente na construção de narrativas e memórias sobre o processo de como esses grupos se reconhecem como tais e como fazem a manutenção das suas tradições e costumes. É a partir dos encontros, através de um projeto de Teatro de Bonecos realizado em 2016, com as/os ${ }^{3}$ moradoras/es do Território Quilombola Santa Rosa dos Pretos, localizado no município de Itapecuru-Mirim (MA), que busco discutir, neste trabalho, os conceitos de Memórias e Identidades em interface com a Educação Quilombola e, por conseguinte, pensar esse território como contexto e texto (CARRIL, 2017) para a sala de aula.

Este artigo é fruto da pesquisa de mestrado que está sendo desenvolvida, desde primeiro semestre de 2019, no Programa de Pós-Graduação Profissional em História da África, da Diáspora e dos Povos Indígenas da Universidade Federal do Recôncavo da Bahia e, acima de tudo, é fruto da árvore de vivências, aprendizagens e troca de saberes em Santa Rosa dos Pretos (MA). Este território-encruzilhada, que tive contato ainda na graduação, em 2016, orienta/ou meus passos;fortalecendo-me nessa sociedade-mundo que apaga, silencia e impossibilita a existência - do epistemicídio ao genocídio - dos meus/nossos, o povo negro. A árvore de vivências e aprendizagens que nasceu naterra pretadesse território-encruzilhada brotou um fruto e ele está amadurecendo. A investigação do mestrado é este fruto, e ela se insere no campo das discussões sobre Educação Quilombola, tendo comolocus de análise a escola quilombola Unidade Escolar Básica Elvira Pires, localizada em Santa Rosa dos Pretos (MA), o qual aprofundarei em outro momento. Nesse sentido, não pretendo apresentar um quadro mais amplo da pesquisa, uma vez que a mesma se encontra em andamento, optei apenas em tensionar alguns aspectos e problemáticas presentes no recorte deste estudo.

No primeiro momento do texto, apresento o contexto sócio-histórico do campo da pesquisa, para falar sobre o modo de fazer e ser dentro do território, desde a manutenção de suas tradições culturais até a produção de identidades quilombolas, que são construídas/atualizadas, feitas e desfeitas para se fazer o viver/resistir em contextos de expropriação de terras, os conflitos ambientais. Para discussão deste tópico, trago os trabalhos

\footnotetext{
${ }^{2}$ No Brasil, existem 1.695 comunidades quilombolas com processo abertos e 179 tituladas, segundo dados da Comissão Pró-índio de São Paulo. Mais detalhes em: http://cpisp.org.br/. Acessado em 03 de julho de 2019.

${ }^{3}$ Optei por este formato na elaboração do texto por uma preocupação com as questões de gênero na linguagem, tentando escapar do monopólio que é o uso do artigo "masculino" e como forma de questionamento da representação do feminino em nossa sociedade e na produção do conhecimento. Uso o duplo a/o por entender que o duplo o/a, geralmente usado por este mesmo motivo, ainda me provocaincomodo, pois a meu ver segue reproduzindo a ideia de subalternidade do gênero feminino, "o que vem depois". Além do mais, o duplo a/o me possibilita também referenciar as vozes das mulheres/meninas/senhoras quilombolas, participantes do projeto de extensão, que emergirão ao longo do texto.
} 
de conclusão de curso ${ }^{4}$ de moradoras do território Anacleta Pires da Silva (2017) e JosicléiaPires da Silva (2017) para dialogar com Beatriz Nascimento (1987), Stuart Hall (2006), Aníbal Quijano (2010) e AiméCésaire (1978).

Em seguida, inicio uma discussão sobre Memória Oral a partir das narrativas de mulheres quilombolas, relacionadas ao cotidiano, à luta e aos processos de resistência, acionadas nas oficinas do projeto de Teatro de Bonecos "Histórias e Memórias Quilombolas em cena", que desenvolvi como bolsista do grupo PET Conexões de Saberes: Comunidades Populares/UFMA, na comunidade Santa Rosa dos Pretos, durante o ano de 2016. Para tanto, promovo diálogos entre as narrativas orais desse processo com Pollak (1989), Bosi (2002) e Silva (2017). Além de analisar o Território Quilombola Santa Rosa dos Pretos como contexto e texto (CARRIL, 2017) nas atividades do projeto de Teatro de Bonecos para, das reflexões emergidas nesse espaço criado de educação não formal, pensar a prática pedagógica na educação formal da escola quilombola.

Nas considerações finais, defendo a construção do conhecimento pautada nos saberes dos nossos, os subalternizados (mulheres, quilombolas, pretas/os, pobres, indígenas etc.). Faço alguns apontamentos sobre a Educação Quilombola, considerando o debate sobre Memórias e Identidades tensionado e as formas de transmissão de saberes na manutenção das tradições e costumes dentro do território.

2. Santa Rosa dos Pretos (MA): Território e Identidades Quilombolas

"Eu sou do samba/ sou da capoeira/ sou do Tambor de Crioula/Sou da matriz africana/ Sou do povo Quilombola/ Sou da África e da Angola/ Eu também sou da Umbanda." (Canção do álbum Resistência Quilombola "Dalva e Ana - inspiração da Natureza" ${ }^{5}$ ).

O Território Quilombola Santa Rosa dos Pretos está localizada às margens da BR-135, no município de Itapecuru-Mirim - MA, a 86 quilômetros da capital do Estado do Maranhão, a ilha de São Luís, sendo um dos territórios quilombolas do Estado que possui uma forte trajetória de luta pela regularização fundiária e de direitos assegurados por leis. As/os moradoras/es fazem a manutenção do território por meio da memória e das narrativas orais das/os suas/seus anciãs/ões, assim elas/es preservam seus costumes e manifestações culturais e

\footnotetext{
${ }^{4}$ Trabalhos monográficos apresentados e elaborados por moradoras de Santa Rosa dos Pretos (Itapecuru-Mirim MA) que se formaram em Licenciatura em Pedagogia da Terra pela Universidade Federal do Maranhão (UFMA) em convênio com o Programa Nacional de Educação em Áreas de Reforma Agrária (PRONERA).

${ }^{5}$ Disponível em: https://www.youtube.com/watch?v=he7Tc5XgFoY\&list=PLtVJJQXNyyMPCP9Fm_d2KS1Un0RR1DO3\&index=1
} 
religiosas que vem sendo passada de geração em geração, "das/os mais velhas/os à/aos mais novas/os".

Para Anacleta Pires da Silva (2017), liderança de Santa Rosa dos Pretos, na sua monografia "Resistência e Trajetória de Luta pela Regularização Fundiária do Território Quilombola Santa Rosa dos Pretos":

O Território quilombola de Santa Rosa dos Pretos foi criado a partir da invasão dos portugueses no território, que é dito hoje como brasileiro. Sabemos que este ato ilícito foi premeditado por ter como a porta de entrada os interesses europeus com a visão de explorar este tão falado Brasil descoberto. Mas o certo seria dizer que o Brasil seria de terras invadidas pela cobiça das riquezas naturais. Partindo deste pressuposto e junto a ele, a busca forçosa pelos negros do continente africano fez com que negros fossem escravizados no Brasil (SILVA, 2017, p. 30).

Uma narrativa que a História, a tida como oficial, insiste em apagar, silenciar ou romantizar nas entrelinhas construídas no que nos é epistemologicamente posto - dos livros, escola, mídia etc. ao imaginário popular - como História do Brasil, pautada numa historiografia homogeneizante e excludente. A obra "Crítica da razão negra", de AchilleMbembe (2014), nos ajuda a compreender, os pilares que sustentavam a estrutura racista na história europeia, da qual nós, brasileiras/os, bem como todas/os as/os americanas/os, somos herdeiras/os. A história do racismo é a história do capitalismo, uma trama de submissão e exploração dos corpos, de uso e abuso dos seres nele capturados, por meio de operações e estruturas teóricas e discursivas, com efeitos perversos na prática.

O que acontece/u em Santa Rosa dos Pretos e em todo continente americano pode ser entendido, segundo Aníbal Quijano (2010), como “colonialidade da classificação social universal do mundo capitalista", ou seja, o que começou na América "foi mundialmente imposto. A população de todo o mundo foi classificada, antes de mais, em identidades 'raciais' e dividida entre os dominantes/superiores 'europeus' e os dominados/inferiores 'nãoeuropeus"” (QUIJANO, 2010, p. 107).Sobre a relação colonizador-colonizado, AiméCésaire (1978) afirma:

Entre colonizador e colonizado, só há lugar para o trabalho forçado, a intimidação, a pressão, a polícia, o imposto, o roubo, a violação, as culturas obrigatórias, o desprezo (...). Nenhum contacto humano, mas relações de dominação e de submissão que transformam o homem colonizador em criado, ajudante, comitre, chicote e o homem indígena em instrumento de produção (CÉSAIRE, 1978, p. 25).

No período colonial, os europeus invadiam continentes - África e América - e matavam, exploravam e escravizavam os povos, pretas/os e indígenas, pelo o que Silva (2017) chama de “cobiça das riquezas naturais". Sob este pano de fundo, onde hoje é o território quilombola Santa Rosa dos Pretos, situava-se a Fazenda Santa Rosa que pertenceu, até meados de 1898, ao invasor irlandês o Barão Joaquim Raimundo Nunes Belfort (1820-1898). O patriarca da família 
irlandesa no Brasil, Lourenço Belfort, estabeleceu-se no Maranhão por volta de meados do séc. XVIII, foi o precursor da criação do bicho da seda no Brasil, dedicando-se em larga escala, à cultura do arroz, anil e algodão. Na época, foram trazidas sete famílias de negras/os escravizadas/os sequestradas/os de Guiné-Bissau para o trabalho escravo na Fazenda Santa Rosa $^{6}$. Elas tinham como chefes: Judith Pires, Amância Pires, Filete Pires, Antônia Pires, Filipe, Olímpio Pires e Olivia Pires (SILVA, 2017).

Após a "abolição", em 1888, muitas/os ex-escravizadas/os permaneceram trabalhando na Fazenda Santa Rosa, passando de cativas/os a agregadas/os do Barão Belfort. É importante destacar que a falta de iniciativas do governo para integrar a/o ex-escravizada/o na sociedade, de forma que fossem asseguradas/os por lei (acesso à educação, saúde, moradia etc.), contribuiu para que os antigos senhores, muitas vezes, continuassem explorando as/os negras/os "libertas/os".

Resultado das revoltas das/os negras/os escravizadas/os e/ou da falência da produção da fazenda após 1888? Não se sabe. Mas “o Barão Joaquim Raimundo Nunes Belfort deixou em seu testamento a área que era reconhecida como centro de lavoura para uso fruto perpétuo desses ex-escravizados 7 " (SILVA, 2017, p. 32). As sete famílias trazidas à força do continente africano para serem escravizadas na Fazenda Santa Rosa, no Maranhão, se perpetuaram, resistiram, dando origem à aproximadamente 800 famílias que compõem atualmente o território quilombola Santa Rosa dos Pretos que, por sua vez, é composto por 20 quilombos: Boa Vista, Pirinã, Barreiras, Leiro, Centro de Águida, Fugido, Barreira Funda, Sítio Velho, Picos I, Picos II, Curva de Santana, Alto de São João, Tingidor do Campo, Colégio, Kelru, Santa Rosa dos Pretos, além de Matões, Fazenda Nova, Pindaíba e Conceição, nos quatro últimos são quilombos de dentro do território que foram tomados por fazendeiros (SANTOS, 2019, p. 48).

Os territórios autônomos de negras/os, africanas/os e afrodescendentes receberam diferentes nomes ao longo do continente americano. Na história do Brasil, são conhecidos como “quilombos" ou “mocambos". Segundo Beatriz Nascimento (1987, p. 303), quilombo é “um conceito próprio dos africanos bantos e que vem sendo modificado através dos séculos". Em 1740, na ocasião do Conselho Ultramarino, pela primeira vez os quilombos foram fortemente associados à ideia de fuga, ao isolamento geográfico e a um número mínimo, especificamente

\footnotetext{
${ }^{6} \mathrm{O}$ documentário "O Mundo Negro tem mais Vida" apresenta detalhadamente este contexto histórico. Disponível em: https://www.youtube.com/watch?v=zc4Ok8h3aEc\&t=1533s.

${ }^{7} \mathrm{Na}$ transcrição do testamento do Barão, datada de 1925, há o seguinte trecho: "Deixo para uso e fruto de America Henriques e todos seus filhos a data de terras no lugar Santa Rosa, (...) podendo roçar nas mesmas terras, sem ônus algum, todos aqueles que me serviram como escravos, durante sua vida e a dos seus, não podendo em tempo serem vendidas, alienadas, ou dadas a pagamentos as ditas terras que constituem um patrimônio perpétuo aos acima declarados e seus descendentes".
} 
cinco, de indivíduos que juntos deram início a um território (NASCIMENTO, 1987, p. 303). Segundo Lélia Gonzáles (1982), no período escravista, os quilombos “existiram em todo o país como a contrapartida, o modo de resistência organizada do povo negro contra a superexploração de que era objeto (p. 36)".

Para Beatriz Nascimento (1987), em "Introdução ao conceito de Quilombo":

Esta indefinição a respeito do que seja um quilombo leva os historiadores a ampliar seu conceito. Na tradição popular, ele é assim definido: quilombo era um estabelecimento singular, que segundo Edilson Carneiro, sofreu variações geográficas, de tipos de sistemas econômicos (Palmares se estabeleceu na zona açucareira a Rio das Mortes, na zona mineradora) e de etnias que o compunham. Estas variações também foram sofrendo modificações através do tempo como imaginário histórico e social (NASCIMENTO, 1987, p. 303-304).

Entende-se por quilombos, segundo o Instituto Nacional de Colonização e Reforma Agrária (INCRA),

(...) grupos étnicos - predominantemente constituídos pela população negra rural ou urbana -, que se autodefinem a partir das relações específicas com a terra, o parentesco, o território, a ancestralidade, as tradições e práticas culturais próprias. (...) As terras ocupadas por remanescentes das comunidades dos quilombos são aquelas utilizadas para a garantia de sua reprodução física, social, econômica e cultural. ${ }^{8}$.

Entretanto, para Anacleta Pires da Silva (2017), moradora do território quilombola Santa Rosa dos Pretos:

Em Santa Rosa dos Pretos, porém, "quilombo" é entendido como um lugar de liberdade, onde as forças coletivas se mantêm através das resistências cultural, econômica e política. É um espaço sagrado e de proteção demarcado pelos negros, ou melhor, pretos revoltados, frente ao amaldiçoado tráfico negreiro imposto pelos brancos europeus, que violaram sua condição humana, econômica e cultural. Percebese, desta forma, que a noção de quilombo e território carregam para nós uma história, mas não qualquer história (SILVA, 2017, p. 25-26).

O lugar de liberdade mencionado por Silva (2017) vive resistindo a constantes violações. Além dos conflitos de terra, a luta contra fazendeiros ou contra o próprio Estado, e do processo de regularização fundiária, outras formas e sistemas de colonizações e explorações impactam o território quilombola Santa Rosa dos Pretos através dos projetos desenvolvimentistas $^{9}$, frutos da Globalização. O território encontra-se fatiado pela modernidade. Afetado pela Estrada de Ferro Carajás (EFC), operada pela companhia mineradora VALE S.A., pela ferrovia Transnordestina São Luís-Teresina, rodovia BR-135 e o risco da sua duplicação, dois linhões da Companhia Energética do Maranhão (CEMAR),

\footnotetext{
${ }^{8}$ Informações disponíveis em: 〈http://www.incra.gov.br/quilombola> Acessado em 01 de julho de 2019.

${ }^{9} \mathrm{Na}$ lógica dos projetos desenvolvimentistas que afetam desde os anos de 1950 povos e comunidades tradicionais. O desenvolvimento é entendido como meio para melhores condições de vida, enquanto os territórios tradicionais “espaços vazios” a serem ocupados (SANTOS, 2019).
} 
chamados Coebinha, e mais três que pertencem à companhia Eletronorte chamados Coheb Grande.

Flávio dos Santos Gomes, em "Mocambos e quilombos: uma história do campesinato negro no Brasil (2015)", salienta que os movimentos sociais, como o Movimento Negro, articulando discussões com os setores políticos, conseguiram na constituinte de 1988, assegurar no artigo $\mathrm{n}^{\mathrm{o}} 68$ dos Atos das Disposições Constitucionais e Transitórias (ADCP) o reconhecimento e a posse das terras historicamente ocupadas pelos quilombos, através da certificação da Fundação Cultural Palmares (FCP) e a titulação e demarcação pelo INCRA. O autor ainda assinala que, entretanto, muitos são os processos que encontram-se em tramitação que lutam por reconhecimento, cidadania, terras e políticas públicas de educação e saúde. A obra de Flávio dos Santos Gomes discute a formação e desenvolvimento do campesinato negro no Brasil, desde o início da colonização portuguesa do país até a situação contemporânea das comunidades quilombolas em sua luta pelo acesso à terra e pelo reconhecimento e demarcação dos territórios, além dos embates contra os projetos desenvolvimentistas ou até mesmo os muitos interesses do capital/Estado.

Atualmente, osterritórios quilombolas atingidos por estradas e linhões no Maranhão sofrem violações constantes dos seus direitos socioambientais, além de impactos na segurança alimentar, a poluição sonora e do ar, interferência nas dinâmicas sociais, assoreamento dos igarapés etc. $\mathrm{O}$ aumento dos trens e suas paradas constantes, por exemplo, têm dificultado a travessia, causando riscos de atropelamentos e morte (SILVA, 2017). São nessas lâminas do desenvolvimento que as identidades quilombolas são construídas/atualizadas, feitas e desfeitas para se fazer o viver-resistir em contextos de expropriação de terras e de conflitos ambientais. Segundo Stuart Hall (2011), em "Identidades Culturais na Pós-modernidade”, a identidade:

É definida historicamente, e não biologicamente. O sujeito assume identidades diferentes em diferentes momentos, identidades que não são unificadas ao redor de um "eu" coerente. Dentro de nós há identidades contraditórias, empurrando em diferentes direções, de tal modo que nossas identificações estão sendo continuamente deslocadas (STUART, 2011, p. 13).

Nesse sentido, as identidades quilombolas seriam construídas e reconstruídas a partir de relações não permanentes, tornando-se uma "celebração móvel” que é "formada e transformada continuamente em relação às formas pelas quais somos representados ou interpelados nos sistemas culturais que nos rodeiam" (HALL, 2011, p.13), seja a cultura negra ancestral que permanece nos costumes e tradições do território quilombola, ou pelas novas intervenções oriundas do processo de globalização, no caso de Santa Rosa dos Pretos: os projetos desenvolvimentistas. 
Esse contexto sócio-histórico em que se constitui/u, o local onde está situada e as estratégias e relações estabelecidas dentro e fora de Santa Rosa dos Pretos são elementos que configuram como o território se reconhece como quilombola. Aspectos que também influenciam na construção de narrativas e memórias para a manutenção das suas tradições e costumes. Segundo Silva (2017):

O território quilombola Santa Rosa dos Pretos possui um extenso calendário de festejos e festas e que vem cultivando desde os tempos da escravidão. É o território mais festível da região. Possui um festejo tradicional do Divino Espírito Santo em duas etapas, sendo em novembro e janeiro. Quatro festas também do Divino Espírito Santo, em agosto, setembro e em outubro, dança do coco, tambor de mina, tambor de crioula, terecô de caixa, bumba-meu-boi de Zabumba, carnaval, festa de Nossa Senhora da Conceição, Dom Lázaro, São Benedito, Santo Antônio, Nossa Senhora Santana, São Raimundo, São João, São Patrício, Santa Rosa, Ginga Africana e festas dançantes (SILVA, 2017, p. 39).

As toadas do Tambor de Crioula, as doutrinas do Tambor de Mina (religião de matrizes africanas), a roda da dança do coco, a coroação das imperatrizes e imperadores do Festejo do Divino, os versos das caixeiras são elos, entrelaçamentos, do passado com o presente, na rememoração do ser quilombola e que ganha corporeidade/forma quando o tambor esquenta, quando a coreira dança ou quando as crianças entram na roda e tocam a sua maneira as cabaças, até mesmo quando as vozes roucas das/os mais velhas/os ecoam no terreiro de Tambor de Mina. Josicléia Pires da Silva (2017), jovem liderança de Santa Rosa dos Pretos, ao refletir sobre os impactos dos projetos desenvolvimentistas instalados no território, diz:

\footnotetext{
(...) entendemos que o processo de modernização, na verdade é uma ação genocida que busca aniquilar as culturas das sociedades nativas englobando a isso as suas particularidades, suas expressões e principalmente sua fé e ancestralidade. Na lógica desse mundo moderno, as formas de envolvimento dos territórios quilombolas, como: Tambor de Mina (Matriz Africana), Tambor de Crioula, Festejo do Divino, Dança do Coco, Terecô de Caixa do Divino, Bumba Boi, dentre outras, formas de expressão, comunicação e mobilizações, não se assemelham as monoculturas globalizadas, por tanto não servem ou cabem no moderno, pois são formas únicas e diferentes, ou seja, são sociedades que detém de conhecimentos e entendimentos próprios, constituídas de seu protagonismo e autonomia (SILVA, 2017, p. 16).
}

Destaco que essas manifestações culturais e religiosas são estruturas que orientam e intervém no modo de se fazer/ser quilombola, na manutenção das tradições que vem sendo passada de geração a geração, no cotidiano da vida no quilombo. Além de se tratar de processos de construção de novas epistemes e por isso se faz necessário serem levadas em consideração na sala de aula da escola que está inserida nesse contexto territorial.

Quando Josicléia Pires da Silva (2017) afirma que os territórios quilombolas “detém de conhecimentos e entendimentos próprios", nos faz refletir o papel da escola na formação dos sujeitos. Dessa forma, pensar em Educação Quilombola, o debate a seguir, é pensar que o Território não só se apresenta como contexto para a prática pedagógica, mas como texto, ou 
seja, como um cofo ${ }^{10}$ de conhecimentos e saberes que precisam ser acionados na sala de aula para construção de uma educação que se assuma contra-hegemônica e emancipadora.

3. Memória Oral e Educação Quilombola: o território como contexto e texto no Projeto de Extensão em Santa Rosa dos Pretos (Itapecuru-Mirim - MA)

A educação e o acesso à escolarização são pautas das lutas de negras e negros no Brasil, tornando-se pontos centrais para alcançarmos a nossa emancipação e liberdade. Desde o período da escravidão, os quilombos já se preocupavam com o ensino-aprendizagem das/os quilombolas. Durante a Revolta da Balaiada, que eclodiu no Maranhão entre 1838 e 1841, por exemplo, o líder Negro Cosme já demonstrava essa preocupação, é dele a primeira iniciativa que se tem registro da criação de uma escola de ensino de leitura e escrita no quilombo, especificamente no Quilombo Lagoa Amarela (CUNHA, 1999) que situava-se onde hoje é o município de Chapadinha (MA), minha cidade natal.

Neste momento, busco analisar o significado e as formas que a educação pode assumir no contexto da singularidade territorial quilombola, considerando o papel da memória oral na transmissão de saberes e na manutenção das tradições e costumes. Para tanto, trago nesta discussão, os questionamentos emergidos de um espaço de educação não formal ${ }^{11}$, criado há três anos no Território Quilombola Santa Rosa dos Pretos (MA) para refletir o fazer pedagógico na educação formal da escola quilombola. Esse espaço de educação não formal é o Projeto de Teatro de Bonecos "Histórias e Memórias Quilombolas em cena".

Em 2016, ainda no curso de Licenciatura em Teatro, da Universidade Federal do Maranhão (UFMA), como bolsista do Programa de Educação Tutorial PET - Conexões, sob a tutoria da Profa. Dra. CíndiaBrustolin, tive o primeiro contato com o Território Quilombola Santa Rosa dos Pretos (MA), campo de atuação e pesquisa do grupo PET. Na época, eu já desenvolvia oficinas e ações de Teatro de Bonecos em outros espaços de educação não formal, investigando a potencialidade estético-pedagógica dessa linguagem artística em interface à educação das relações étnico-raciais ${ }^{12}$. Após as primeiras viagens à Santa Rosa dos Pretos (MA)

\footnotetext{
10 Espécie de cesto oval, feito de palhas da palmeira do Babaçu (fruto nativo da Região do Maranhão, Piauí e Ceará), no qual é usado para guardar alimentos (farinha, feijão, milho, peixe etc.).

${ }^{11}$ Segundo o Ministério da Educação do Brasil (MEC), a educação formal é aquela que ocorre nos sistemas de ensino tradicionais; a não formal corresponde às iniciativas organizadas de aprendizagem que acontecem fora dos sistemas de ensino; enquanto a informal e a incidental são aquelas que ocorrem ao longo da vida.

${ }^{12}$ Esta pesquisa resultou no meu trabalho de conclusão de curso "O Negro no Teatro de Bonecos: das tradições de teatro de bonecos à sala de aula da Educação Básica”, com orientação do Prof. Dr. Tácito Freire Borralho.
} 
para conhecer o seu contexto sócio-histórico, propus ao grupo PET o projeto de extensão como um espaço de troca de saberes com o Território Quilombola.

Durante o "I Seminário Território de Luta: Memórias dos Guardiões de SantaRosa dos Pretos"13, realizado em março de 2016, na Escola Quilombola Elvira Pires, planejamos e elaboramos com moradoras/res do território quilombola o projeto de Teatro de Bonecos "Histórias e Memórias Quilombolas em cena". O projeto surgiu com a proposta de um resgate histórico-cultural de memórias da comunidade e com o objetivo de incorporar os conhecimentos da cultura africana e afro-brasileira no desenvolvimento das atividades das oficinas, reconhecendo que a historicidade local é repassada pela oralidade.

Nesse sentido, destaco a presença e importância das/osMestras/es Griôs, responsáveis pela salvaguarda da História dos povos e comunidades tradicionais, pois são elas/es as/osfiandeiras/os da memória: tecem e costuram os fios do Tempo através dos fazeres e saberes do Território, das práticas culturais. Respeitadas/os pelas sociedades africanas, as/os griots mantêm vivos os costumes. Apesar dos avanços da escrita e da tecnologia, o papel delas/es não ficou obsoleto, permanece vivo. "Cada ancião que morre é uma biblioteca que se queima”. A frase, de Amadou Hampaté Bâ no seu texto “A Tradição Viva (1982)”, expressa a importância da tradição oral no continente africano e a sensação de ouvir uma/um sábia/o africana/o relatar suas experiências: é como se vários livros se abrissem, com uma profusão de detalhes, para dar voz às histórias e às tradições locais. No Território Quilombola Santa Rosa dos Pretos não é diferente, são as/os chamadas/os "guardiãs/ões do quilombo" que exercem esse papel.

Levando em consideração a importância da oralidade para os povos e comunidades tradicionais, apresentamos, na ocasião do I Seminário Território de Luta, a esquete de teatro de bonecos "Zé Baleco e o Velho Simaúma" 14 , elaborada a partir das narrativas orais registradas pelo grupo PET durante as idas ao território e que retratou a história do igarapé Simaúma que antes dava sustento para as famílias do Território Quilombola Santa Rosa dos Pretos, e que atualmente encontra-se em risco de extinção por conta dos impactos provocados pela passagem da Estrada de Ferro Carajás no território. Naquele momento, ficou nítido o interesse pelo projeto nos olhares do público, e que logo em seguida foi verbalizado na fala de Seu Libânio Pires (83 anos), liderança política do território: "Esses bonequinhos vão descobrir a realidade do meu ser, vão despertar a minha memória". A memória define o que é comum a um grupo e o que o

13 O seminário foi realizado pelo Grupo de Estudos Desenvolvimento, Modernidade e Meio Ambiente (GEDMMA-UFMA) e com o apoio do grupo PET Conexões - Comunidades Populares/UFMA.

${ }^{14} \mathrm{O}$ vídeo da apresentação está disponível em: https://www.youtube.com/watch?v=YN5z1y8kCVA\&t=6s 
diferencia dos outros, fundamenta e reforça os sentimentos de pertencimento e as fronteiras socioculturais que vão definir aqueles que são de dentro dos que chegam de fora (POLLAK, 1989).

As entrevistas, conversas e vivências realizadas em idas para o território quilombola permitiram uma proximidade com o histórico de luta e resistência do território e a participação das mulheres frente aos conflitos de terra e de mulheres que as antecederam, remontado muitas vezes ofícios de mulheres no período da escravidão na localidade. A memória oral ganha contorno no processo de luta, regulando a identidade desse território pelos vínculos entre o presente e o passado, reforçando a organização social (BOSI, 2002). A rememoração é elaborada com base nas necessidades atuais, pelas tensões dos sujeitos em viver-resistir em contexto de expropriação de terras, além de outros aspectos, como identidade e modos próprios de ser, viver e fazer.

O projeto teve a duração de um ano e participação de cerca de 20 integrantes, mulheres e crianças. Inicialmente, trabalhamos com leitura de contos e lendas africanas e afro-brasileiras que conduziam discussões em torno dos estudos da identidade, história e memória afrobrasileira. Em seguida, o grupo e as participantes do projeto trabalharam com oficinas de confecção e animação de bonecas Abayomi ${ }^{15}$ e criação de cenas curtas de Teatro de bonecos a partir de narrativas orais coletadas do cotidiano do Território Quilombola Santa Rosa dos Pretos e em conversas com as/os mais velhas/os, ou como também são chamadas/os: as guardiãs e os guardiãos.

Anacleta Pires da Silva (2017) afirma que as/os guardiãs/ões, fontes da memória oral do quilombo, são de grande importância para a manutenção do território:

\begin{abstract}
O marco mais significante de todo o processo histórico do território são os guardiões, porque são as fontes de sabedoria para a resistência e a permanência dos descendentes ou ascendentes de africanos no território, por conterem todos os saberes de forma lúcida com toda responsabilidade do passado. Também são presentes na preocupação de deixarem bons frutos da luta para as próximas gerações, através das suas análises e reflexões e que estão sempre presentes nas discussões de maneira conscientes, bem como, nas decisões e em saberem o que é o melhor para qualidade de vida do seu povo. A confiança e a memória dos guardiões se expandem nas rodas de conversas, pois provoca o sentimento de pertencimento aos laços familiares e parte da natureza. A interrelação sempre reiterada e, desse modo, as rodas de conversas tornam-se a base para as ordenações das resistências e permanência na luta pela sustentabilidade do território (SILVA, 2017, p. 47).
\end{abstract}

As guardiãs e guardiões do quilombo também podem ser entendidas/os como professoras e professoresque ensinam à geração mais nova do território, saberes e conhecimentos que são chaves da manutenção dos costumes e tradições do cotidiano no

\footnotetext{
${ }^{15}$ Boneca preta feita de tecido feita com nó e/ou trança, sem cola e sem costura.
} 
quilombo, ou seja, transmissores de saberes, pois:

(...) preservam as histórias por meio dos contos dos saberes e experiências da vida cotidiana. Isto é ensinamentos dos saberes e o momento em que reafirmam seus compromissos e responsabilidade de manterem os saberes memoriais. A potência da expressão dos saberes, a dimensão das trocas e os conhecimentos das sequências orais são atributos que fazem com que sejam compreendidos e respeitados todo o processo histórico da ancestralidade e da territorialidade (SILVA, 2017, p. 47).

Para Carril (2017), ao discutir os desafios da Educação Quilombola no Brasil e pensar o território como texto e contexto:

\begin{abstract}
É nesse sentido que as narrativas das comunidades quilombolas se transformam em história de vida, promovendo significados às suas condições presentes ligadas ao território. O território tem sua fala expressa por meio do recontar o passado e atualizar tradições vinculadas à vida nos lugares para as crianças e jovens, à organização social que luta pela garantia da permanência nas terras. Reforçam, assim, as bases para a territorialidade, que nada mais é que o território vivido, mais que suporte físico, sendo elemento simbólico de poder e pertencimento (CARRIL, 2017, p. 559).
\end{abstract}

Percebe-se, assim, o quanto é necessário reconhecer, incentivar e promover ações que valorizem os saberes ancestrais contidos na memória oral do território quilombola dentro do ambiente escolar, contribuindo para uma pedagogia que permita as aprendizagens tradicionais sem perder de vista aquilo que nos insere no contexto singular do território Santa Rosa dos Pretos. Entendendo que a memória oral que emerge do coletivo compõe uma tessitura de saberes e conhecimentos que podem transformar as relações entre o Território Quilombola e a Escola.

Silva (2017) reforça o papel das/os guardiãs e guardiões em contrapartida às formas de educação que não levam em consideração o contexto e os saberes dos sujeitos da aprendizagem:

Com as atuais formas de ensino e aprendizagem, distantes de seu processo pessoal, ou seja, que não permite a interação do sujeito à sua realidade; os guardiões revelam uma grande abertura e disponibilidade ao manterem para si responsabilidade de criarem caminhos para se relacionarem com esse novo tempo cheio de novas questões e desafios. Transmitir os conhecimentos deixados pelos antepassados há tempos tem sido uma tarefa árdua. A troca dos saberes é uma ferramenta central para sustentabilidade do conhecimento (SILVA, 2017, p. 48).

Contudo, é fundamental um diálogo da escola com essas mestras e mestres do saber popular, como já defendia Paulo Freire (1991), patrono da Educação Brasileira e educador que lutou pela construção da educação popular. No entanto, Freire (1991) nos orienta que para a realização deste diálogo:

Não devemos chamar o povo à escola para receber instruções, postulados, receitas, ameaças, repreensões e punições, mas para participar coletivamente da construção de um saber, que vai além do saber de pura experiência feito, que leve em conta as suas necessidades e o torne instrumento de luta, possibilitando-lhe transformar-se em sujeito de sua própria história(FREIRE, 1991, p. 16).

De acordo com a metodologia de horizontalidade e participação da comunidade no 
planejamento e execução das oficinas de Teatro de Bonecos, realizadas em círculos-rodas, observei que as narrativas e as encenações eram voltadas à representação do cotidiano, com dramaturgias e personagens negras elaboradas ${ }^{16}$ com base em seus papéis sociais (lideranças, professoras, religiosas, pescadoras etc.), bem como em suas rotinas dentro do Território Quilombola, como a organização de festejos importantes, como a Festa do Divino, e a execução de tarefas centrais nas festividades, o cuidado em comum com a horta, a participação em momento de enfrentamento na luta pela titulação do território. Identidades como a de caixeira, quilombola, lavradora e mãe-de-santo são acionadas constantemente em diversos momentos do cotidiano no Território Quilombola.

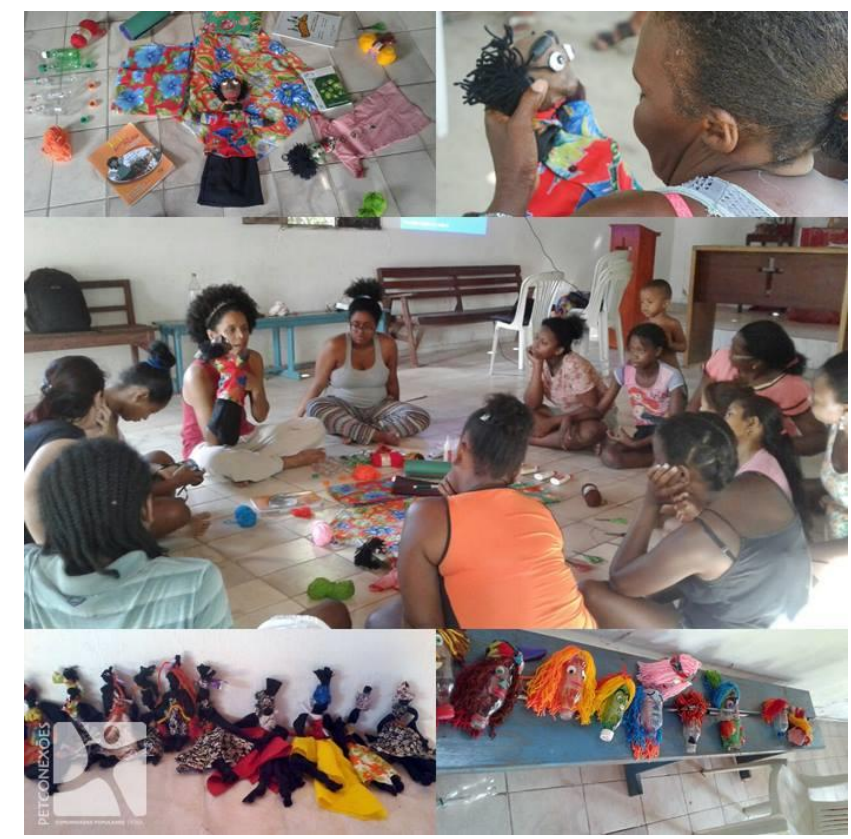

Figura 1 - Fotomontagem das oficinas realizadas no projeto de Teatro de Bonecos. Fonte: Arquivo do Grupo PET Conexões - Comunidades Populares/UFMA, 2016.

As mulheres, jovens e guardiãs ocuparam e ocupam na história de Santa Rosa dos Pretos (MA) importantes papéis sociais, demonstrando força e representatividade. É importante apontar que entre os processos de reconhecimento de importância dos papéis exercidos pelas mulheres de Santa Rosa dos Pretos está o fato que as escolas ${ }^{17}$ do Território Quilombola foram nomeadas com nomes de mulheres antigas que viveram o "tempo da escravidão": Elvira Pires e Mamãe Olivia. Acionar e trabalhar essas memórias orais na sala de aula é uma forma de

\footnotetext{
${ }^{16}$ Vídeo das improvisações disponível em: https://www.youtube.com/watch?v=S7jHFCuq814\&t=92s

${ }^{17} \mathrm{O}$ Território Quilombola possui as seguintes escolas, fruto das reivindicações das lideranças: Creche Mamãe Olívia; Unidade Integrada Barão de Santa Rosa, Unidade Escolar Básica Quilombola Elvira Pires e o Anexo Newton Neves. A U. E B. Quilombola Elvira Pires, o locus da minha pesquisa de mestrado que está em andamento, foi inaugurada em 21 de julho de 2013, e atualmente o prédio abriga alunos das demais escolas, incluindo da creche Mamãe Olívia (PEREIRA, 2017).
} 
contribuir para desconstrução das questões de gênero na educação, como o machismo e a ideia da fragilidade da mulher.

Este trabalho desenvolvido no território quilombola me levou ao encontro do Sankofa, um símbolo africano quefaz parte de um conjunto de ideogramas chamados adinkra, representado por um pássaro que volta a cabeça à cauda. Este símbolo, assim como as guardiãs e os guardiões de Santa Rosa dos Pretos (MA), tem muito a nos ensinar. Ele pode ser traduzido como "retornar ao passado para ressignificar o presente e construir o futuro". Dessa forma, defendendo uma pedagogia Sankofa, isto é, uma pedagogia que reconheça os saberes ancestrais do sujeito da aprendizagem para que ele ressignifique, reflita e questione o seu presente e construa e projete, a partir da troca dos saberes na sala de aula, o seu futuro. Essa construção é produção de conhecimento, é decolinial, é se rebelar e irem sentido inverso ao projeto do epistemicídio impregnado nas nossas escolas - do livro didático à prática pedagógica.

Nesse sentido, o texto "Pedagogia Decolonial e Educação Antirracista e Intercultural no Brasil (2010)" de Vera Candau e Luis Fernandes de Oliveira, aponta que além de uma luta decolonial de poder e de saber, para as/os afrodescendentes a colonialidade do ser é fator relevante nas disputas epistêmicas no campo educacional. A partir do conceito de Interculturalidade Crítica de Catherine Walsh (2005), as/os autoras/es salientam que é possível afirmar que as disputas em torno de políticas afirmativas no campo educacional além de apresentarem caráter epistemológico e político, também se caracterizam como um "projeto de existência e de vida". Para Walsh (2006), o conceito de interculturalidade:

é central à (re)construção de um pensamento crítico-outro - um pensamento crítico de/desde outro modo -, precisamente por três razões principais: primeiro porque está vivido e pensado desde a experiência vivida da colonialidade [...]; segundo, porque reflete um pensamento não baseado nos legados eurocêntricos ou da modernidade e, em terceiro, porque tem sua origem no sul, dando assim uma volta à geopolítica dominante do conhecimento que tem tido seu centro no norte global. (WALSH, 2005, p. 25)

Nota-se que, para a autora, a interculturalidade tem um significado intimamente ligado a um projeto social, educacional, cultural, político, ético e, acima de tudo, epistêmico em direção à descolonização e à transformação da sociedade. Assim, é necessário que todos os dispositivos legais que foram criados para reconhecimento das diferenças, inclusão das demandas tanto das/os negra/os quanto das/os indígenas, questionem as estruturas e as lógicas que produziram/em as diferenças e hierarquizações, inclusive as epistêmicas, naquilo que Quijano (2010) vai denominar de "Colonialidade do Conhecimento". E, infelizmente, nas escolas ainda impera a colonialidade como prática que está enraizada. 
A partir das atividades do Projeto de Teatro de Bonecos, constatei que "identificar os diversos modos de vida no território, criar a percepção das formas de uso dos recursos, da etnicidade e da memória deve integrar o processo educacional" (CARRIL, 2017, p. 558). Neste caso, estamos falando de território como contexto, isto é,

Todas as pessoas e instituições se encontram no território, daí apreendê-lo como contexto, pois ele fala sobre a história do país, sobre a formação social e sobre as comunidades quilombolas. É essa história que implica nas continuidades e descontinuidades dos modos de vida, das estratégias de sobrevivência, das exclusões e das permanências. (CARRIL, 2017, p. 558).

Dessa forma, pensar Santa Rosa dos Pretos como contexto territorial para a sala de aula nos leva ao texto quilombola, que fala de sua territorialidade (CARRIL, 2017). Para a autora, a territorialidade:

(...) passa a ser o ponto de partida da realidade social para a construção de um processo pedagógico significativo, pois a memória, por meio das narrativas vinculadas ao território vivido, permite a análise da história mais ampla em que se inserem as comunidades, na formação social e territorial brasileira (CARRIL, 2017, p. 559).

Entende-se a territorialidade como texto que permitirá no processo de ensinoaprendizagem das/os alunas/os quilombolas uma análise do seu contexto sócio-histórico e cultural e da história mais ampla em que se inserem os territórios quilombolas e, nesse sentido, um dos avanços que ocorreu no âmbito das políticas afirmativas brasileiras foi a aprovação da resolução $n^{\circ}$ 8, de 20 de novembro de 2012, que definiu as Diretrizes Curriculares Nacionais para a Educação Escolar Quilombola na Educação Básica (DCN):

Uma proposta de educação quilombola necessita fazer parte da construção de um currículo escolar aberto, flexível e de caráter interdisciplinar, elaborado de modo a articular o conhecimento escolar e os conhecimentos construídos pelas comunidades quilombolas. Isso significa que o próprio projeto político-pedagógico da instituição escolar ou das organizações educacionais deve considerar as especificidades históricas, culturais, sociais, políticas, econômicas e identitárias das comunidades quilombolas, o que implica numa gestão democrática da escola que envolve a participação das comunidades escolares, sociais e quilombolas e suas lideranças. Por sua vez, a permanência deve ser garantida por meio da alimentação escolar e a inserção da realidade quilombola em todo o material didático e de apoio pedagógico produzido em articulação com a comunidade, sistemas de ensino e instituições de Educação Superior (BRASIL, 2012, p. 26.).

Contudo, ainda existem inúmeras lacunas na Educação Quilombola, envolvendo as condições dos estabelecimentos escolares, a formação dos docentes e o uso e acesso de recursos didáticos apropriados. Essas lacunas dificultam a construção de um processo pedagógico significativo nas escolas situadas em territórios quilombolas. Portanto, deve-se levar em consideração essas problemáticas no campo da discussão sobre a Educação Quilombola.

Ademais,a temática sobre Educação Escolar Quilombola é absolutamente contemporânea no cenário da política pública de Educação do Brasil. No que tange ao currículo, 
as DCN enuncia que pensar o currículo da Educação Escolar Quilombola não significa permanecer estagnado apenas ao passado histórico ou fixo no contemporâneo. Significa, acima de tudo, buscar elos entre os tempos históricos e as dimensões socioculturais. As DCN também destaca que a Educação Escolar Quilombola compreende escolas quilombolas e escolas que atendem estudantes oriundas/os dos Territórios quilombolas.

A Educação Escolar Quilombola se configura como uma ação afirmativa que visa ir contra a corrente hegemônica da colonialidade do saber imbricada nas práticas pedagógicas escolares e, sobretudo, acionar os saberes/conhecimentos dos territórios quilombolas no processo de ensino-aprendizagem das/os educandas/os.

O Projeto de Teatro de Bonecos "Histórias e Memórias Quilombolas em cena" foi um divisor de águas, não apenas para minha formação como professor-pesquisador preocupado com a práxis pedagógica, mas para entender que para uma educação como prática libertadora, defendida por Paulo Freire, é necessário o reconhecimento e o tornar visível as identidades, saberes e contextos dos nossos, aquelas/es que a sociedade insiste em silenciá-los: mulheres, pretas/os, quilombolas, indígenas, faveladas/os etc.

\section{Considerações Finais}

Com base no debate sobre Memórias e Identidades tensionado anteriormente e as formas de transmissão de saberes na manutenção das tradições e costumes dentro do Território Quilombola Santa Rosa dos Pretos (MA), bem como as reflexões sobre o território como contexto e texto para a sala de aula, percebi que um dos grandes desafios de quem educa e forma estudantes em comunidades quilombolas é valorizar a tradição oral numa sociedade que prioriza a língua escrita. A Educação Quilombola, assim como toda educação com pretensão democrática e emancipadora, deve reconhecer os saberes da criança ao chegar à escola. E os saberes ancestrais são as bases e as raízes desses territórios.

Para as comunidades quilombolas, o pensar e o fazer são indissociáveis, ao contrário do ambiente escolar que valoriza o saber sobre o fazer. É de suma importância que a Escola deixe de construir e desenvolver processos de ensino-aprendizagem que tratam, ideologicamente, como se todos fossem "iguais", tornando invisíveis as diversidades culturais de identidades.

Ao apresentar o contexto sócio-histórico do Território Santa Rosa dos Pretos (ItapecuruMirim - MA) e o modo de fazer e ser dentro desse território, desde a manutenção de suas tradições culturais até a produção de identidades quilombolas, que são construídas/atualizadas, feitas e desfeitas para se fazer o viver e resistir em contextos de conflitos ambientais, percebe- 
se o quanto a memória oral funciona como um encruzo entre o presente e o passado que carregam saberes que são linhas que compõem as tramas de resistência desse território.

Nas narrativas de mulheres quilombolas, sobre o cotidiano, a luta e os processos de resistência, emergidas durante as oficinas do projeto de Teatro de Bonecos realizado em Santa Rosa dos Pretos, memórias e identidades foram acionadas nos possibilitando refletir a prática pedagógica na educação formal da Educação Quilombola. Pensar no território como contexto e texto para sala de aula é compreender que os saberes que emergem da territorialidade precisam ser trabalhados no processo de ensino-aprendizagem de alunas e alunos quilombolas, entendendo que suas tradições e costumes compõe a cosmovisão dos seus territórios, ou seja, possuem maneiras subjetivas de entender o mundo e formas próprias de ser/estar nele.

Apontei durante o texto algumas formas de aprender e ensinar das/os quilombolas de Santa Rosa dos Pretos (MA) presentes no cotidiano do quilombo ou nas suas tradições e costumes, ou seja, as pedagogias quilombolas, como aspectos fundamentais para a construção de um currículo escolar quilombola. Percebo, então, que a Educação Escolar tem que ser vista e construída como indissociável da realidade do contexto em que a escola está inserida e deve manter um diálogo com a diversidade cultural, as identidades, os conhecimentos, de modo a realizar uma ligação entre o Território Quilombola e a Escola, construindo assim uma pedagogia Sankofa na sala de aula.

\section{Referências}

BOSI, Ecléa. Cultura e desenraizamento. In: BOSI, Ecléa. A Cultura brasileira. Temas e situações. São Paulo: Ática, 2002. p. 13-41.

BRASIL. Diretrizes Curriculares Nacionais para a Educação Escolar Quilombola na Educação Básica. Brasília, DF: MEC/CNE/CEB, 21 nov. 2012. Seção 1, p. 26.

CARRIL, Lourdes de Fátima Bezerra. Os desafios da educação quilombola no Brasil: o território como contexto e texto. Revista Brasileira de Educação, v. 22, n. 69, abr.-jun. 2017.

CÉSAIRE, Aimé. Discurso sobre o colonialismo. Lisboa: Sá da Costa, $1^{\text {a }}$ edição, 1978.

CUNHA, P. M. C. C. Da senzala à sala de aula: como o negro chegou à escola. In: OLIVEIRA, L. (org.). Relações raciais no Brasil: alguns determinantes. Niterói: Intertexto/UFF: 1999.

FREIRE, Paulo. A Educação na Cidade. São Paulo: Cortez; 1991.

GOMES, Fernando dos Santos. Mocambos e Quilombos: uma história do campesinato negro no Brasil. São Paulo: Ed. Claro Enigma, 2015. 
GONZÁLES, Lélia. A mulher Negra na Sociedade Brasileira. In. LUZ, Madel T. (org.). $O$ Lugar da Mulher: Estudos sobre a Condição Feminina na sociedade atual. Rio de Janeiro: Edições Graal, 1982.

HALL, Stuart. Identidades culturais na pós-modernidade. Rio de Janeiro: DP\&A, 2011.

HAMPATÉ BÂ. A tradição viva. In: A história geral da África, V.I. SP, Ática, UNESCO, 1982.

MBEMBE, Achille. A Crítica da razão negra. Lisboa: Antígona, 2014.

NASCIMENTO, Beatriz. Introdução ao conceito de Quilombo. In: NASCIMENTO, Beatriz; SIQUEIRA, José Jorge; LOPES, Helena Theodoro. O Negro e a Cultura no Brasil: Pequena Enciclopédia da Cultura Brasileira. Rio de Janeiro: UNIBRADE - Centro de Cultura/UNESCO, 1987.

OLIVEIRA, Luís, Fernandes de; CANDAU, Vera Maria Ferrão. Pedagogia Decolonial e Educação Antirracista e Intercultural no Brasil. In: Educação em Revista. Belo Horizonte, v. 26, n 01, p. 15-40. Abril, 2010.

PEREIRA, Maria Francisca Rocha Enes. Programa Saúde na Escola (PSE): uma análise da percepção dos moradores sobre programa dentro da escola quilombola Elvira Pires no Território Quilombola Santa Rosa dos Pretos, município de Itapecuru-Mirim/MA no ano de 2016 e 2017. Bacabal/MA, UFMA, 2017. Monografia de Graduação do curso de licenciatura em Pedagogia da Terra - PRONERA/UFMA.

POLLAK, Michael. Memória, esquecimento, silêncio. In: Estudos Históricos, Rio de Janeiro: vol. 2, nº 3, 1989.

QUIJANO, Aníbal. Colonialidade do Poder e Classificação Social. In: SANTOS, Boaventura de Sousa; MENESES, Maria Paula. (Orgs.) Epistemologias do Sul. São Paulo; Editora Cortez. 2010. 637 páginas.

SANTOS, Dayanne da Silva. Não se pode entrar na terra de encantado sem permissão: um estudo sobre a relação de pessoas e encantados na luta pelo território quilombola Santa Rosa dos Pretos (Itapecuru-Mirim - MA). São Luís/MA, UFMA, 2019. Dissertação de Mestrado em Ciências Sociais - UFMA.

SILVA, Anacleta Pires da.Resistência e trajetória de luta pela regularização fundiária do Território Quilombola Santa Rosa dos Pretos. Bacabal/MA, UFMA, 2017. Monografia de Graduação do curso de licenciatura em pedagogia - PRONERA/UFMA.

SILVA, Josicléa Pires da.A Riqueza e a Pobreza ao longo do Corredor Carajás: os impactos dos projetos de mineração nos territórios quilombola Santa Rosa dos Pretos e Monge-Belo. Bacabal/MA, UFMA, 2017. Monografia de Graduação do curso de licenciatura em Pedagogia da Terra - PRONERA/UFMA.

WALSH, C. Pensamiento crítico y matriz (de)colonial. Reflexioneslatinoamericanas. Quito: EdicionesAbya-yala, 2005. p. 13-35. 